\title{
Reversible MRI Changes in the Splenium Related to Recent Cessation of Antiepileptic Medications
}

\author{
McLaren $\mathrm{J}^{1 *}$, Misra $\mathrm{A}^{1}$ and Chu $\mathrm{CJ}^{1,2}$ \\ ${ }^{1}$ Department of Neurology, Massachusetts General Hospital, USA \\ ${ }^{2}$ Harvard Medical School, USA
}

\section{Case}

A 21-year-old male with history of refractory epilepsy presented for long-term video EEG monitoring. His home antiepileptic medications were weaned off over a seven-day period. On hospital day 4 , he had a right temporal electro clinical seizure with secondary generalization and a second right temporal electrographic seizure. On hospital day 8 , MRI brain identified an ovoid circumscribed lesion in the splenium of the corpus callosum which had not been present on prior scans (Figure 1). This characteristic lesion is thought to be induced by a rapid reduction of antiepileptic drugs, not with toxic drug effects or seizure frequency. It requires no further investigation [1].

\section{References}

1. Gürtler S, Ebner A, Tuxhorn I, et al. (2005) Transient lesion in the splenium of the corpus callosum and antiepileptic drug withdrawal. Neurology 65: 1032-1036.

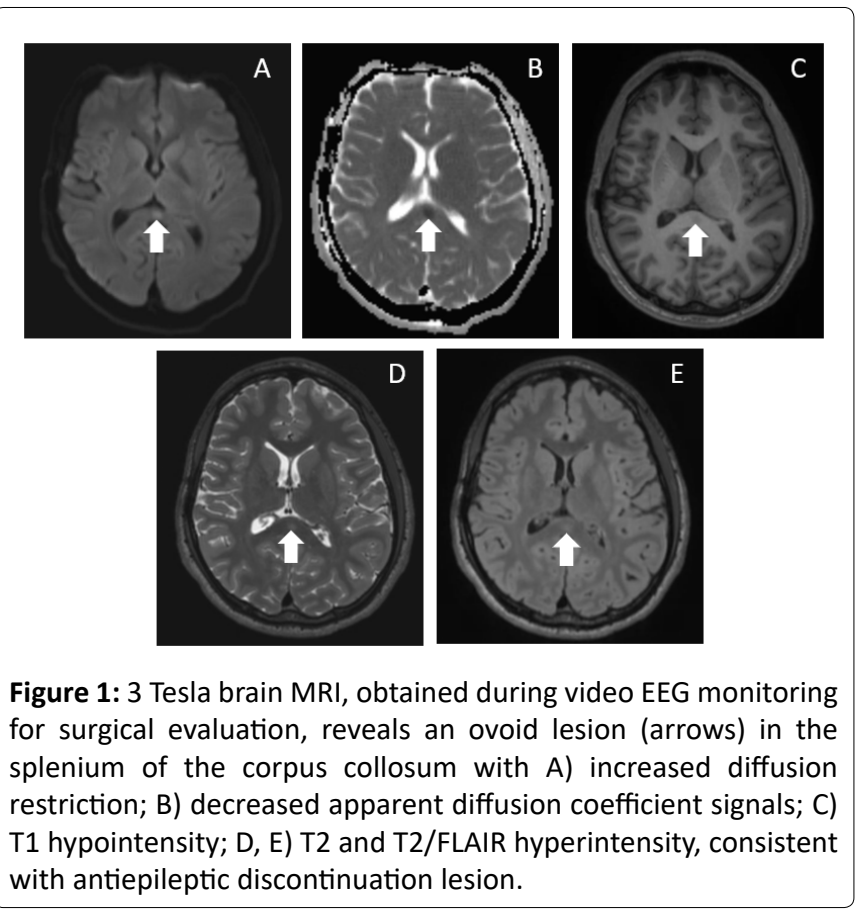

*Corresponding author: John R McLaren, Department of Neurology, Massachusetts General Hospital, 175 Cambridge St, Suite 340, Boston, MA 02140, USA, Tel: 617-726-6540, Fax: 617726-0230

Accepted: July 22, 2021

Published online: July 24, 2021

Citation: McLaren J, Misra A, Chu CJ (2021) Reversible MRI Changes in the Splenium Related to Recent Cessation of Antiepileptic Medications. J Pediatr Neurol Neurosci 5(2):141-141 